\title{
EFFECT OF PARTICLES TYPE, VELOCITY, AND IMPACT ANGLE ON SLURRY EROSION OF STAINLESS STEEL USING SIMPLE TEST RIG
}

\author{
Tawfik Tawfik El-Midany ${ }^{1}$, Abdou Abdel Fattah Abdel Samad ${ }^{1}$, Ahmed \\ Mohamed Galal Abdel Menam ${ }^{1}$ and Yaser Sood Abdel-Aziz Saleh ${ }^{2}$ \\ ${ }^{1}$ Department of Production Engineering and Mechanical Design Mansoura University, \\ Faculty of Engineering \\ ${ }^{2}$ B. Sc. (Eng.), M. Sc.
}

\begin{abstract}
The present work is a study of the effect of slurry particle type, impact angle, and velocity, and test duration time on the erosion process of stainless steel 316, 304. Erosion change the surface geometry of the parts, components of machines that will affect the performance and efficiency of the parts may be causing the parts failure. Mud or sand particles were used in water with concentration of $40 \mathrm{wt}$. \%. The particle maximum dimension is $550 \mu \mathrm{m}$. Specimens velocities were $2.3 \mathrm{~m} / \mathrm{s}$ and $5.75 \mathrm{~m} / \mathrm{s}$ using a simple test rig was designed and fabricated to investigate slurry erosion and cavitation erosion. This is done by rotating the specimens in a transparent tank containing slurry with the desired composition and concentration with a fluid. The velocity of specimens can be from zero m/s up to $14 \mathrm{~m} / \mathrm{s}$.

The specimen weight loss of the eroded sample was examined and was evaluated. The weight loss is measured using a balance with sensitivity of $0.0001 \mathrm{~g}$, and the surface is photography using SEM examination.

Results show that; the increase of particles hardness results in increase the weight loss. And increase the testing time affecting the wear rate. Also increase velocity increasing weight loss.
\end{abstract}


Impact angle has a great effect on weight loss. Test rig results come in agreement with the previous theoretical and experimental results. It is concluded that test rig is valid to investigate the slurry erosion and cavitation erosion due to different parameters.

\section{KEYWORDS : Slurry erosion, particles type, Impact angle, pot tester, Stainless Steel 304, Stainless Steel 316, Erosion resistance}

\section{INTRODUCTION}

Erosion wear is a very crucial parameter for selection and design of slurry transportation systems as it affects directly to the economy of equipment. The service life of equipment is limited due to erosion wear. Many segments of industry can benefit from the availability of better slurry erosion resistant equipment. So many researchers studied and still study the effect of different parameters on slurry erosion and cavitation phenomenon to control the effect of them on the equipment. The studies were both theoretical and experimental investigation.

Erosion is a complex phenomenon, which depends on large number of parameters such as particle size, type, shape, and velocity, together with the flux of erosive particles and their angle of impact. Clearly, the site of impact is subjected to extremely high stress, strain, and strain rates, and there is now evidence that local heating can be generated by the impact energy. Oxidation can therefore be induced; the erosion of a surface by abrasive particles in an inert fluid should depend on the number of particles striking the surface, their velocity and their direction relative to the surface.[1,2, and 3]

Some theoretical analysis studied different parameters which affect the slurry erosion and cavitation phenomenon. The parameters responsible for slurry erosion are solid particle concentration, impact velocity of erodent on the target surface, impact angle, erodent particle size and shape, and hardness of the striking particle sand target material.[4, 5, 6]

\section{DIFFERENT TYPES OF TEST RIGS}

Different types of test rigs are designed and constructed for studying some parameters affecting the erosion. So that the relative velocity between specimens and slurry can be simulated by two ways; moving slurry with fixed specimens or rotates the specimen inside the slurry pot.

\subsection{Solid particle erosion test (ASTM G 76)}

Standard test method for conducting erosion tests by solid particle impingement using gas jets. The dry erosion experiments were conducted using a grit blasting machine which is based on pressurized air to accelerate sand particles. Two different incident angles of $90^{\circ}$ and $30^{\circ}$ were used between the nozzle axis and the sample surface.[7]. A test rig used dry and compressed air has a specially designed specimen holder for holding the specimen during the test at the required impact angle, but also apply a suitable stresses required on the specimens. The study show that, increasing the applied tensile loads on the specimen, erosive wear increases. The stress increase on the cross section of the specimen causes changes in the atomic lattice and this increases erosive wear. Results show that the impact angle affects the erosion rate. The maximum erosive wear rate lies between $20^{\circ}$ and $30^{\circ}$. and the maximum erosion rate was obtained at $30^{\circ}$ impinging angle. However; as the angle increases the erosion rate is seen to decrease. [8]

\subsection{High Liquid Pressure Liquid Erosion Test (ASTM G 73)}

High pressure liquid (with / without solid particle) impingement erosion test (ASTM G 73). A liquid jet impingement erosion test has been performed using sand particles introduced through the water jet's nozzle by a powder feeder. [7]

A liquid impingement erosion test is a test used for assessing the erosion resistance of certain materials. This technique is used to evaluate objects that are exposed to liquid capable of producing cavitations. This technique is not applicable or meant for predicting or testing material resistance against erosion brought by impingement corrosion or particle impingement in flows. Instead it is intended for testing resistance to liquid jets with high velocity, slurries 
and liquids at the surface. [9].Pramod et al (2015) [10] used the test rig to investigate the mean particle size of $655 \mu \mathrm{m}$ was collected as the material retained between the of $600 \mu \mathrm{m}$ and $710 \mu \mathrm{m}$ sizes. The target material is Aluminum alloy 6063 and the solid particles are Quartz, particle size is $655 \mu \mathrm{m}$, solid concentration is $10 \%$ by weight in water fluid. The test time is $60 \mathrm{~min}$. It is observed that the maximum weight loss occurs at $30^{\circ}$ angle of impact and it decreases as angle decreases that is due to the ductility of the target material (AA6063).

Gulovleen, et al. [11] used a specially designed erosive wear test rig. Erosion test was performed on slurry erosion as per ASTM standards G73. The mass loss (in $\mathrm{mg} / \mathrm{cm}^{2}$ ) according to the test shows that erosion rate of AISI 316L stainless steel is more than that of hard faced steel samples. Also the hard faced samples show better performance than the bare steel in all experimental conditions. The maximum erosion takes place at average particle size of $600 \mu \mathrm{m}$, level of concentration is $60,000 \mathrm{ppm}$, size of nozzle diameter $3 \mathrm{~mm}$, angle of impingement is $90^{\circ}$ and velocity of $40 \mathrm{~m} / \mathrm{s}$. The type of hard faced sample also affected the erosion, It is found that hard faced with titanium based alloy are more hard than hard faced with cobalt based alloy and substrate material.

Randall S., et al. (1991) [12] used the erosion pot tester consisted of a circular section stainless steel vessel (5.0 liter) with a central vertical stainless steel shaft supporting two erosion test specimens. The shaft was driven by a $3.7 \mathrm{~kW}$ electric motor. Temperature control of the suspension to be $40 \pm 1{ }^{\circ} \mathrm{C}$ was achieved during test. Erosion specimens were supported by pin ends. They have reported that the mass loss rate in erosion is proportional to the rate of dissipation of kinetic energy of impacting particles sizes between $100 \mu \mathrm{m}$ and $500 \mu \mathrm{m}$, and above $500 \mu \mathrm{m}$ the erosion rate slightly changes with particle size. The test specimens were cylindrical ( copper or steel ) and the test speed of $18.7 \mathrm{~m} \mathrm{~s}^{-1}$ in erosion pot tester using 1.2 wt.\% suspension of $\mathrm{SiC}$ in oil for particle diameters between 20 and $500 \mu \mathrm{m}$. The fluid was diesel fuel oil of density $856 \mathrm{~kg} \mathrm{~m}^{-3}$ and viscosity $2.1 \times 10^{-3} \mathrm{~N} \mathrm{~s} \mathrm{~m}$ at $40 \mathrm{C}$. Cylindrical erosion test specimens $46 \mathrm{~mm}$ long were made either from OFHC copper rod (diameter $5.17 \mathrm{~mm}$ ) for short-time erosion tests or from API PllO casing steel (diameter $4.76 \mathrm{~mm}$ ) for longer-time erosion rate tests.

C.S. Ramesh et al (2011) [13] Investigate the slurry erosive wear using a test rig. They studied the slurry erosion wear behavior of cast and hot extruded A16061 and Al6061$\mathrm{SiC}$ composites in sand slurry. They also studied the effect of velocity, specimen type, and time on erosion. They concluded that there is a significant increase in slurry erosive wear rate of cast and extruded base alloy and its composites with an increase in speed of slurry rotation. Extruded Al6061-SiC composites exhibited better slurry erosive wear resistance when compared with Al6061 alloy and cast Al6061-SiC composites under identical test conditions. Bhupendra K. Gandhi , 2015 [14] developed a pot tester for high impact velocities to evaluate the erosion wear of materials used for hydraulic turbines specially runner blades or buckets. A pot tester is then fabricated by employing the propeller from the bottom of the cylinder, rotating at the minimum speed required for uniform distribution. The test specimens are then mounted at a shaft inserted from the top of the pot and to be rotated at desired test speeds by a different motor. A transparent acrylic cylindrical tank with inside diameter of $310 \mathrm{~mm}$ was mounted on iron frame structure and fixed using nut bolts. He also investigated the Variation of concentration of solids with the propeller speed for particle size of $302.5 \mu \mathrm{m}$ at different solid concentrations by weight ( $1 \%, 2 \%, 3 \%$, and $5 \%$ ) on the water along the height. The test impact velocity was $32 \mathrm{~m} / \mathrm{s}$.

Y. M. Abd-Elrhman, et al 2013 [15] studied slurry erosion tests using a slurry whirling arm rig. The rig consists of three main units: a specimen rotation unit, a slurry unit, and a vacuum unit. Two specimen holders are mounted on the ends of two aligned arms. The rotation diameter for specimens is $248 \mathrm{~mm}$. The rotor is driven by a variable speed motor. The specimen holders have tilting and locking facilities to adjust the required inclination of the test specimen. The specimen rotation unit provides impact velocity. During slurry erosion tests, only the front surface of specimen is exposed to the impinging slurry since the sides of the specimen are held by the specimen holder. The front surfaces of the specimens test surfaces, were of dimensions $23 \mathrm{~mm} \times 10 \mathrm{~mm}$.

H.J. Amarendra, et al (2012) [16] conducted tests in a conventional slurry pot having a circular section of diameter $282 \mathrm{~mm}$ and height of $286 \mathrm{~mm}$. Four baffle plates were placed to 
minimize centrifuging of the fluid inside the pot. Specimen holder was fastened to spindle of the tester through a connecting rod. There was a clearance of $32 \mathrm{~mm}$ between the lower circular plate and the bottom of the slurry pot. The specimen holder had upper and lower plates that could be clamped with fasteners to hold the CIs and specimens. The upper and lower circular ring plates had a diameter of $150 \mathrm{~mm}$ and thickness of $4 \mathrm{~mm}$. The lower circular plate had a centrally punched hole of diameter $75 \mathrm{~mm}$. The spindle was driven by a 3 $\mathrm{kW}$ motor through stepped cone pulley capable of delivering 500, 900 and $1400 \mathrm{rpm}$ speeds.

J.F. Santa, et al. (2007) [17] constructed slurry erosion tests, which were carried out in a modified centrifugal pump, in which the specimens were submitted to wear conditions similar to those of the liners of Francis hydraulic turbines. The testing machine, which is composed of a commercial centrifugal pump connected to an electrical motor, a frequency inverter and an isothermal bath to control the slurry temperature. Mass losses were measured every 30 min by using a scale with $0.0001 \mathrm{~g}$ resolution. The total duration of each test was $120 \mathrm{~min}$, and after that period both the sample and the slurry were replaced.

G. Bazanini, et al. (2008) [18] studied cavitation erosion wear of metallic specimens using the new compact rotating disk device The device consists of a water chamber in which a metallic disk rotates. On the disk surface are located the cavity inducers, that may be holes or protruding pins, and the specimens as well. The disk is fixed on the shaft and may be detached to switch the specimens. A glass cover is mounted on the chamber to visualize the flow and the bubble formation inside. The purpose of the device is to create the bubbles that will be responsible for the erosion of the specimens fixed on the disk surface and close to the inducers. To prevent vibration problems, the holes and the specimens are situated on opposite radial positions of their reciprocals.

Yoshiro Iwai,et al. (2004) [19] developed of a new type micro slurry-jet erosion (MSE) tester for evaluation of wear properties of hard thin coatings. A new pot type MSE apparatus which has new properties was examined using a single crystal $\mathrm{Si}$ wafer specimen as a reference, and a PVD TiN coating for demonstration. The new MSE test is able to assess the wear properties of thin hard coatings independently from the properties of the substrate. Their results indicate that the sensitivity of the MSE test is about 100 times better. This means that the MSE test is much more suitable for evaluation of thin multi-layered coatings, thin coatings with gradients, coating/substrate interfaces, etc. than the ASTM test.

Murugan K et al. (2015) [20] investigated the effect of impingement angle and standoff distance using water jet on Naval brass, they concluded that Naval brass eroded high at an angle of impingement of $30-45^{\circ}$. It shows that naval brass erosion takes place in a ductile mode. Lower angle impingement produces rough surfaces whereas high angle impingement produces craters and surface cracks. While changing the standoff distance no improvement was observed in naval brass erosion.

\subsection{Cavitation erosion vibratory Tribometer (ASTM G 32)}

Kendrick, H. Light (2005) [21] Studied the effect of cavitation erosion on reinforced polymer (GRP) composites using the ASTM G32 vibratory induced cavitation test method. Results from the testing show that a GRP composite system can be designed to greatly increase the cavitation erosion resistance of the material, but this resistance remains below common metallic materials. A solution identified during this study involves the use of durable elastomer materials as the protection mechanism.

\subsection{Erosion-Corrosion Test in Pot Rig}

Erosion-corrosion is a complex phenomenon which involves the interaction between the mechanical processes of solid particle erosion and the electrochemical processes of corrosion. A slurry pot erosion tester was used to perform erosion -corrosion experiments. The rig is driven by $3.5 \mathrm{kw}$ motor. Cylindrical test samples, velocity of specimen is $18.7 \mathrm{~m} / \mathrm{s}$, the pot is made of UPVC with a maximum capacity of 4 liters and has a cup type design copper cooler which allows the temperature of the slurry to be controlled. Comparison of erosion and erosion corrosion rates in different test solutions for ss316L and AISI 1020 at velocity $7 \mathrm{~m} / \mathrm{s}$, $1 \%$ sand concentration.[22] A. Toro, et al. (2001) [23] investigated the erosion and corrosion-erosion resistance of a low-carbon gas nitrided martensitic stainless steel tested in 
seawater-quartz slurry. The test was in a pot test. The results were compared to those obtained from commercial AISI 410 and 420 martensitic stainless steels.

Maksim Antonov, et al , ( 2006) [24] investigate Erosion-corrosion of $\mathrm{Cr} 3 \mathrm{C} 2-\mathrm{Ni}$ cermets in salt water using a test rig. The study of the wear-corrosion synergism usually utilizes measurement of the material loss under wear conditions with and without corrosion or under corrosion conditions with and without wear.

\section{TEST RIG}

\subsection{Test Rig Design Consideration.}

In the present work, a test rig was designed and fabricated to enable users to test material specimen for their resistance to slurry erosion and cavitation erosion. This is done by immersing the specimen in a tank contain slurry with the desired composition and concentration with a fluid and then the specimen were allowed to rotate at a specified speed starts from zero up to 900 r.p.m. with the holder shaft. Also if a specimen with a cross section like a pipe or an aerofoil section rotates with high speed in a fluid erosion will occur due to cavitation. The pressure depends on the velocity and the specimen cross section profile.

The relative velocity between specimens and slurry can be controlled by controlling the rotation of specimens holder, $\mathrm{N}$ ( r.p.m ) and the radius from center of rotation the specimen around the axis $(\mathrm{r})$ and the relative velocity $(\mathrm{v}=\mathrm{r} \times \omega)$ where $\omega$ is the angular velocity of

the specimen holder and $\omega=\frac{2 \pi N}{60}$

\subsection{Test-Rig Description}

A mechanical stirrer test rig with accurate rotation control has been designed and constructed to be used as a slurry erosion tester or cavitation erosion for some sections. Figure (1) gives a schematic drawing for the test rig showing its main components. And Fig.(2) shows actual test rig photo. It mainly consists of seven units; namely driving unit (1), power transmission element (2), Jaws unit (3), rotating unit for holding specimens (4), cylindrical tank (5), base frame (6) and protection cover (7).

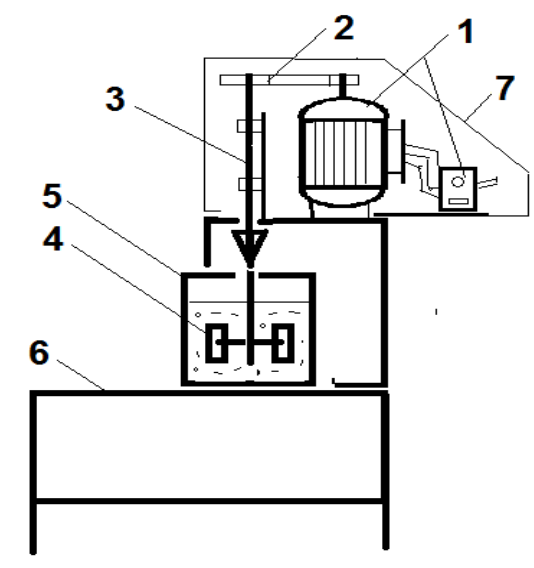

Figure (1) Test Rig schematic drawing showing it's main components.

1- Driving unit

2- Power transmission elements

3- Jaws unit

4- Rotating unit for holding specimens

5- Cylindrical tank

6- Base frame

7- Protection cover

The driving unit (1), as shown in Figures $(1,2)$ consists of a 3-phase induction motor (1 hp., $1400 \mathrm{rev} . / \mathrm{min}$.), which is controled by an inverter type LSIS ( SV-iC5 ). 
The inverter contains 4-way button for parameters setting ( r.p.m., frequancy, ..). The power supply for the inverter is 220 volt, $60 \mathrm{~Hz}$ but the inverter supply a 3-phase for the motor. The inverter controls the output motor speed from zero r.p.m to 1800 r.pm.

The power transmission elements consist of a drive timing pulley with 20 teeth fixed on the motor shaft and drive another driven pulley with 40 teeth with a timing belt. The reduction ratio of the power transimmition is $2: 1$ so the speed of the inverter reading will be divided by two. Specimens can rotate at any required speed from 0.0 up to 900 r.p.m.

Jaws unit consists of three jaws adjusted to hold or leave the rotating specimens threaded shaft. As the outer nut on the jaws unit is tightened, it applies pressure to the tapered section of the jaws unit, forcing the jaws inward holding the rotating shaft. The maximum diameter is to be held in $16 \mathrm{~mm}$.

Rotating Unit for Holding Specimens consists of the main rotating rod, length $(350 \mathrm{~mm})$, which is threaded with M 16 in order to hold the specimens holder on the thread rod and a locking Nut is used to fix the specimens holder in the required position. Holder arms were manufactured for the required test angle. Figures $(3 \mathrm{a}, 3 \mathrm{~b})$ show the rotating unit parts, all parts are mode from stainless steel $304 \mathrm{~L}$ to be wear and corrosion resistant. Maximum length for holder arm is $150 \mathrm{~mm}$, the maximum rotating diameter is $320 \mathrm{~mm}$.

The specimen holder can be changed easily because it is designed to be held on a threaded part, so that different sample holders can be used. Each specimen holder consists of two arms welded in the same line with a threaded hole, M 16 in arms center as shown in Figure (4) to be stable when rotates at high speed and each arm contains at the end of it a hole to support the specimen. This hole on adjust the required impact angle for test.
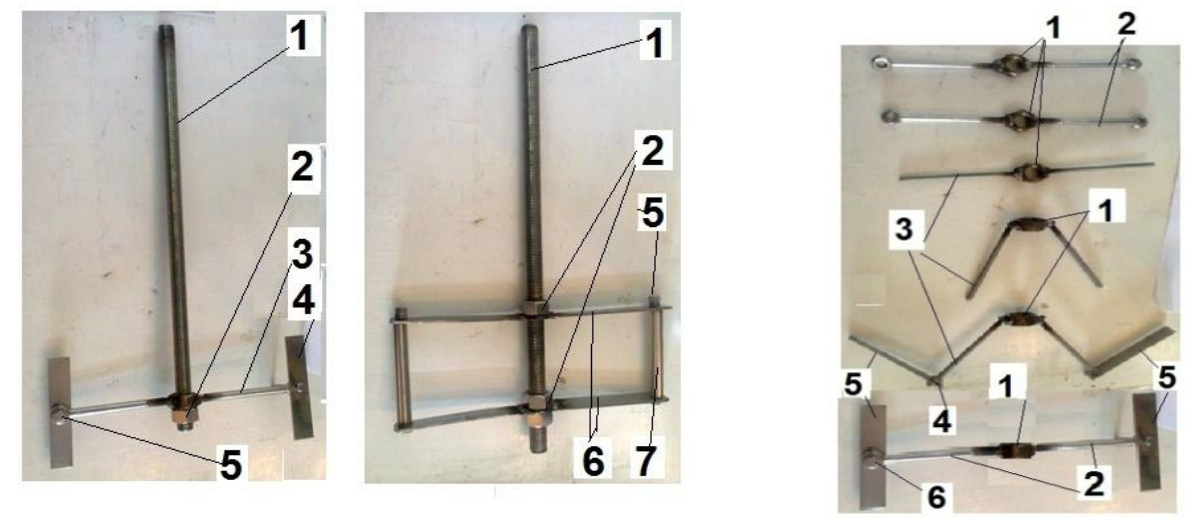

Figure (3a ) Plate, Figure ( $3 b$ ) cylinder

1- rotating thread

3- Holder arm

5- bolt with nuts

7-cylider specimen
2- Nut M 16

4- plate specimen

6- Holder plats

Figure (3) rotating thread, specimen holder, and specimen

The cylindrical tank was made from a cast acrylic transparent material sheet with main dimensions of $6 \mathrm{~mm}$ thickness, diameter $380 \mathrm{~mm}$ and $350 \mathrm{~mm}$ height.

The base frame is rigid enough to support the test rig parts during test. It can be adjusted horizontaly by four adjustable legs. As shown in Figure (2) the test rig frame consists of base frame ( $500 \times 600 \times 1000 \mathrm{~mm}$ ) which stands on four rubber legs with adjustable screws and a second support frame, which supports the driving unit, the power transmission elements, and the jaws unit. 
The protection cover is designed and constructed to cover the motor and the power transmission unit.

\subsection{Preparing For Test}

Investigate particles sizes and particles shapes as shown in Figure (5) using a scanning electronic microscope (SEM) which is used to investigate the slurry erosive surface.
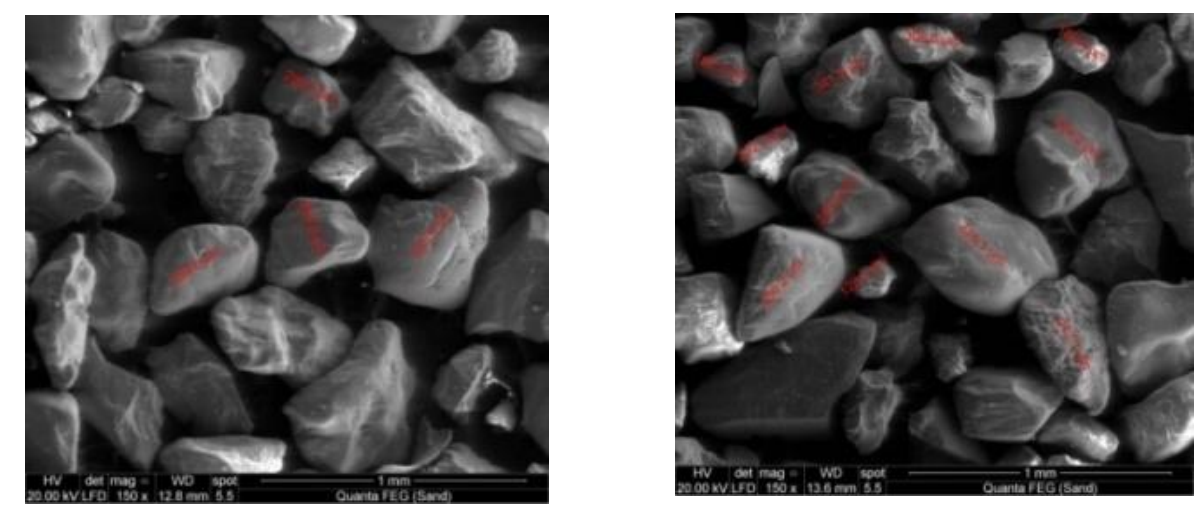

Figure (5) photographic for the particles shapes and sizes

The particles and fluid are weighted using balance with sensitivity $1 \mathrm{gm}$. to prepare the slurry concentration in water.

The test specimens are Stainless steel 316L, and stainless steel 304L. The specimens shape are plate specimens. The plate specimen dimensions are;

$0.7 \pm 0.1 \mathrm{~mm}$ thickness, $20 \pm 1 \mathrm{~mm}$ width, and $100 \pm 2 \mathrm{~mm}$ Long.

Each specimen is identified and it's weight is measured by using an accurate balance with sensitivity of $(0.0001 \mathrm{~g})$.

Specimen holding arrangement is designed and fabricated to hold flat specimen by taking suitable dimensions according to experimental needs. By using this slurry erosion tester, experiments can be carried out for investigating the wear characteristics of various materials which are subjected to slurry erosion. To be sure that the slurry concentration in the fluid is the same, the end of the rotating rod must contain a blower or the specimen itself works as a blower, as in the present work. Figure (6) shows specimens are held with arms and rotating shaft.

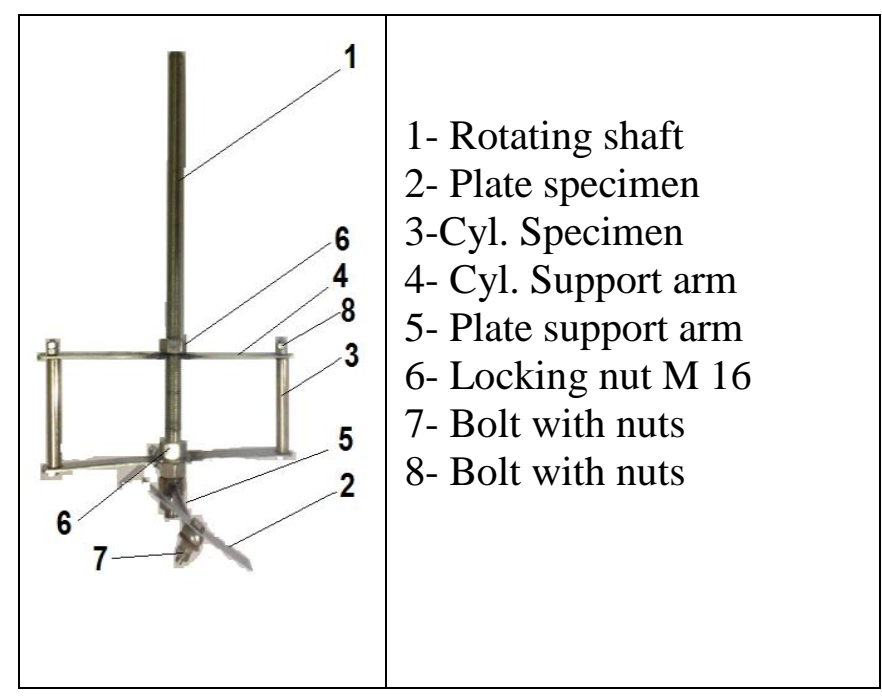

Figure (6) Specimens held are with arms and rotating shaft.

Test Conditions ;

a) Test temperature: $25 \mathrm{C}^{\mathrm{o}}$. 
b) Slurry medium: water

c) Slurry concentration: $40 \mathrm{wt} \%$.

d) Slurry particle size: between 120 $\mu \mathrm{mm}$ and $550 \mu \mathrm{mm}$,

\subsection{Experimental Procedure}

The test procedure to be followed to calculate the erosion wear of different specimens materials for the present test rig were as follow:

1- Cutting each specimen at the required dimensions without affecting its microscopic structure or surface finish.

2- Specimens were cleaned with aceton and then dried with compressed air.

3- Weight each specimen before test. Identify and numbering each specimen at a separate data file to record each step.

4- Holding the specimens to be test on the rotating shaft.

5 - Weigh the required particles and water as per concentration of slurry.

6- Mixing the required particles with water in cylindrical tank.

7- Put the rotating shaft with specimens in slurry and cover the cylindrical tank, and keep the rotating shaft free end out from the cover.

8- Move the cylindrical tank under the jaw unit and fix the rotating shaft free end on the jaw unit very well.

9- Start the motor to rotates at low speed until the slurry becomes homogenous with liquid.

10- Adjust the motor speed to obtain desired test speed.

11- Running the test for the required duration test time.

12- Stop the test and remove the specimen from the specimen holder.

13- Clean and dry the specimen very well.

14- Weighing the specimen after test to measure the weight loss with the same balance and record the new specimen weight after test.

15- Microstructure test for the specimens using SEM and photograph the surface

\section{Test Results}

\subsection{Comparison Between Effect of Sand and Mud Particles on weight loss.}

Figures ( 7 and 8 ) show the effect of mud and sand particles on the weight loss at impact velocities of 2.3 and $5.75 \mathrm{~m} / \mathrm{s}$ respectively, against time.

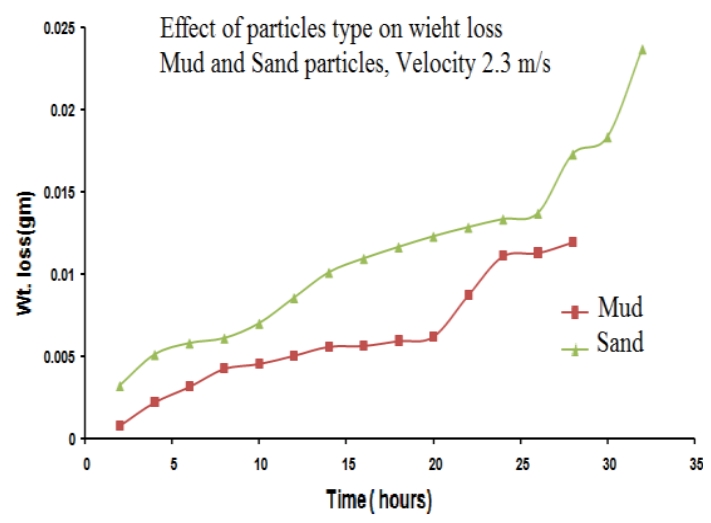

Figure (7): The weight loss in mud or sand with impact velocity $2.3 \mathrm{~m} / \mathrm{s}$

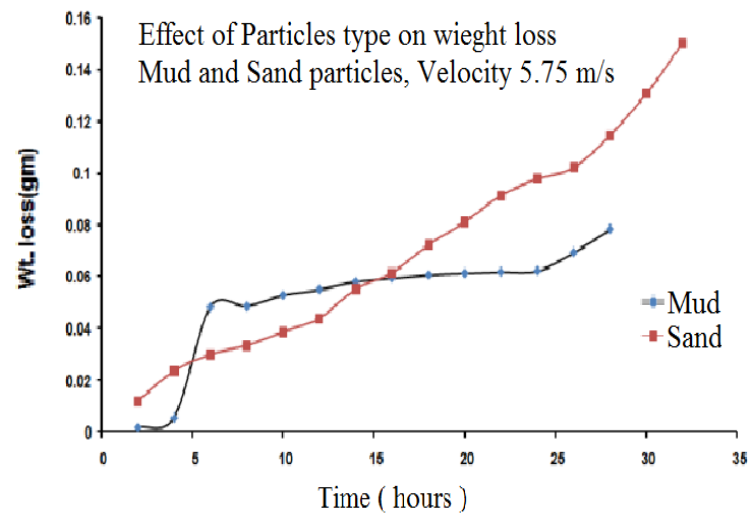

Figure (8): The weight loss in mud or sand with impact velocity $5.75 \mathrm{~m} / \mathrm{s}$

The results are for two groups of specimens from stainless steel 316 at the same test conditions with both mud and sand particles. As shown in the figures, the weight loss at the sand case is higher than mud; also the stages of wear are different. 


\subsection{Effect of impact velocity on Weight loss.}

Figures (9 and 10 ) show the effect of impact velocity on the weight loss for the same particles, mud or sand for stainless steel 316 specimens, against time

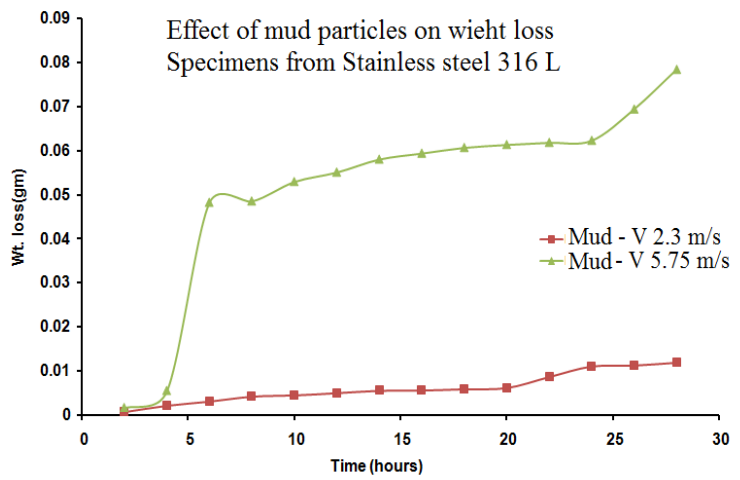

Figure (9): The weight loss, mud, impact velocities $2.3,5.75 \mathrm{~m} / \mathrm{s}$

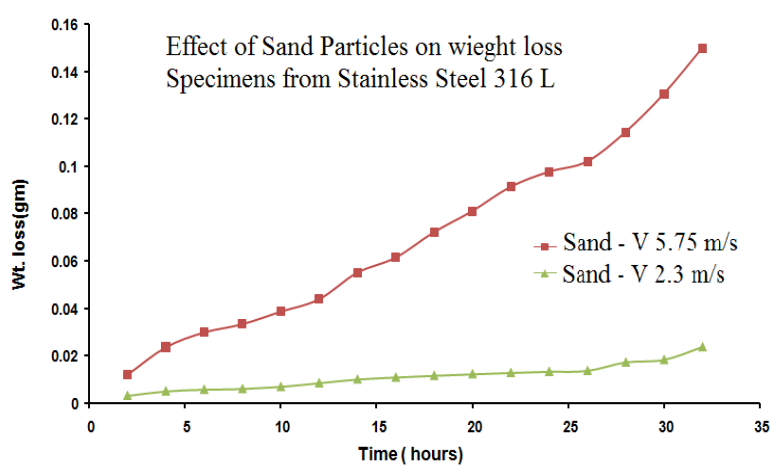

Figure (10) The weight loss, sand, impact velocities $2.3,5.75 \mathrm{~m} / \mathrm{s}$

\subsection{Effect of Impact Angles on Weight loss.}

The test were carried out for different impact angles and stainless steel 304L plate specimens. To study the effect of impact angles on weight loss, different angles for the specimens are used for test under the same conditions. Sand particles in water fluid and sand concentration $40 \mathrm{wt} . \%$ The specimen's velocity is $2.3 \mathrm{~m} / \mathrm{s}$ ). Test duration time is 3 hours; the maximum test time is 18 hours.

The test results for the effect of test duration time on weight loss for specimens with different impact angles for stainless steel 304 specimens are shown in Figure (11). Figure (12) illustrates the variation of weight loss against impact angles at different test duration time. As shown, for different test duration times, the weight losses increas with the increase of the impact angle up to $42^{\circ}$. The maximum weight loss between $42^{\circ}$ and $49^{\circ}$ and the weight loss decrease with impact angle between $50^{\circ}$ and $90^{\circ}$.

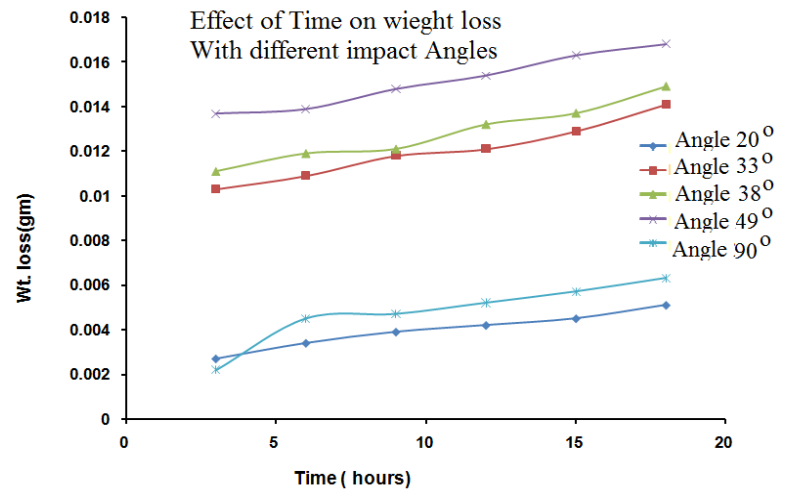

Figure (11): weight loss with time different , velocity is $2.3 \mathrm{~m} / \mathrm{s}$

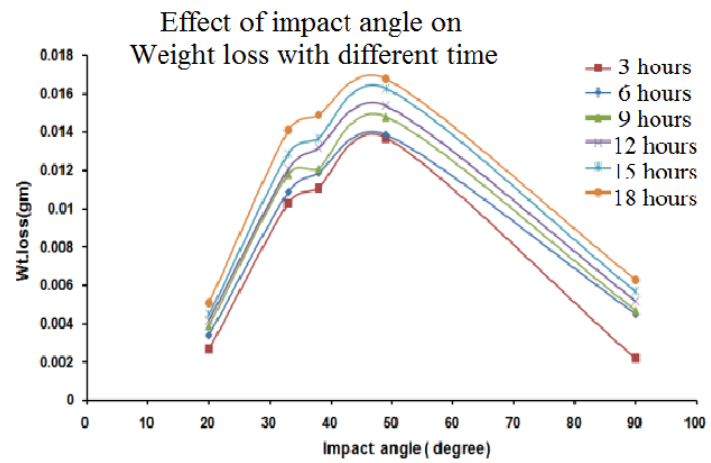

Figure (12): weight loss with different impact angles, , velocity is $2.3 \mathrm{~m} / \mathrm{s}$

As shown the increase in test time results an increase in the weight loss for all impact angles.

\subsection{The Specimens Scanning Electron Microscope photographs}

All specimens are tested at velocity of $2.3 \mathrm{~m} / \mathrm{s}$, sand particle in water with concentration 40 wt. \%. The next figures are for The Scanning Electron Microscope for plate specimens. 


\section{a) Plate Specimens After 9 Hours}

The next Figures (13), (14) are SEM photographs for plate specimens tested up to 9 hours. The impact angles were $33^{\circ}$, and $90^{\circ}$ respectively. The Figures show that wear for impact angle $33^{\circ}$ has higher slurry erosive wear rate than that of impact angle $90^{\circ}$. But for impact angle $90^{\circ}$ the photographs show much more plastic deformation on material surface.
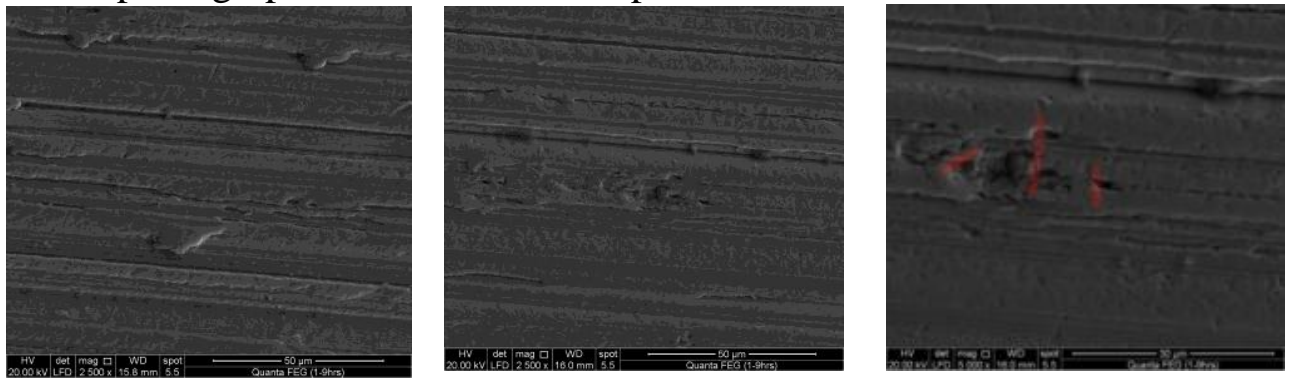

Figure (13), SEM for plate specimen, 9 hours, Impact angle $33^{\circ}$
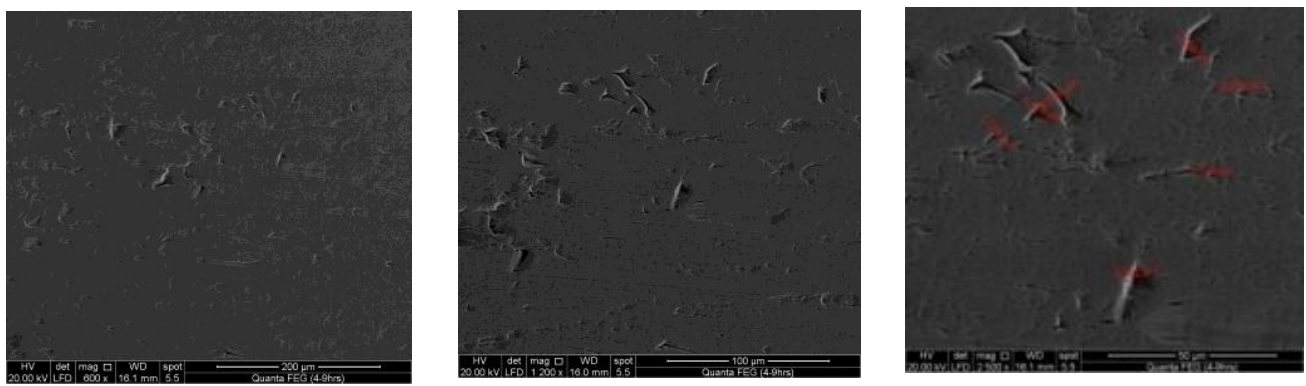

Figure (14), SEM for plate specimen, 9 hours, Impact angle $90^{\circ}$

\section{b) Plate Specimens After 18 Hours}

The next Figures (15), (16) are SEM photographs for plates specimens were tested up to 18 hours, the impact angles were $49^{\circ}$, and $90^{\circ}$ respectively. The Figures shows that wear for impact angle $49^{\circ}$ is higher slurry erosive wear rate than impact angle $90^{\circ}$.
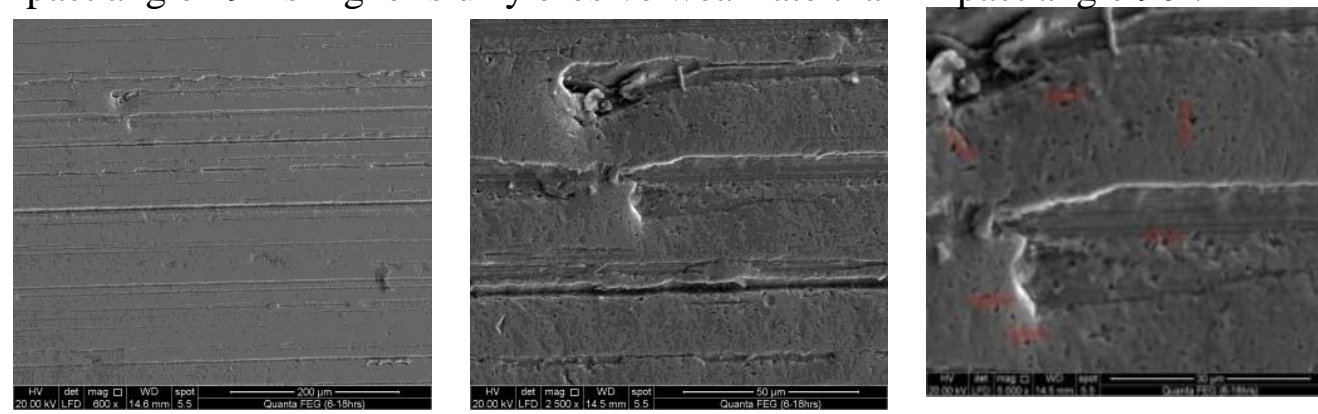

Figure (15), SEM for plate specimen, 18 hours, Impact angle 49o
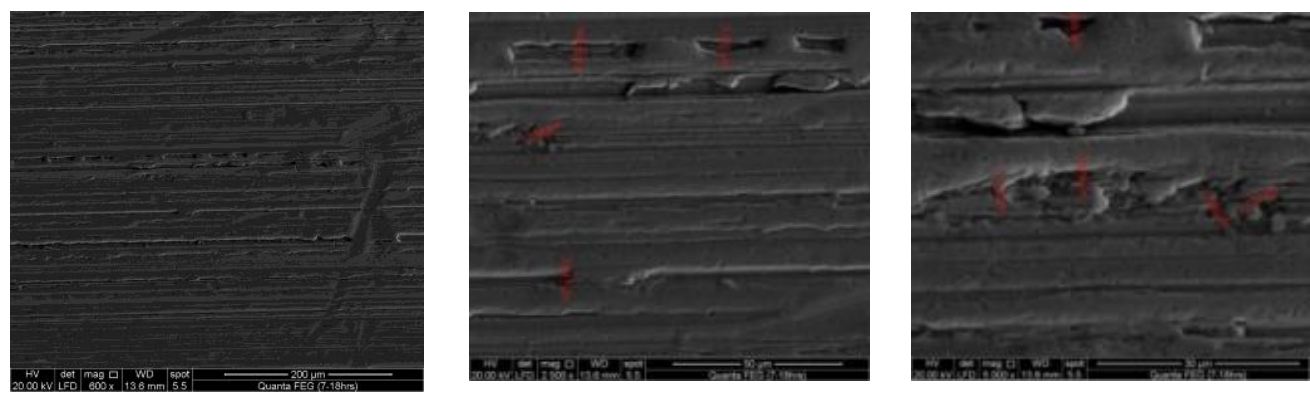


\section{gure (16), SEM for plate specimen, 18 hours, Impact angle 900}

\subsection{The effect of particles type}

Figures (7), (8) are for comparing between effect of sand particles and mud particles on weight loss for stainless steel $316 \mathrm{~L}$, at impact velocities of 2.3 , and $5.75 \mathrm{~m} / \mathrm{s}$ respectively. The results are for two groups of specimens from stainless steel 316 at the same test conditions with both mud and sand particles. The maximum particle size is $550 \mu \mathrm{m}$, the concentration with water is $40 \%$.

The results as shown in Figures (7), (8), the weight loss at the sand case in both cases are higher than mud. The stages of wear are also different. That is due to, firstly the high hardness of sand particles compared with the hardness of mud particles. Secondly, the average of mud particles in size are smaller than sand average sizes.

\subsection{Effect of velocity}

It is clear from Figures $(9,10)$; for both mud particles or sand particles, that the increase in velocity increases the rate of weight loss much more than that due to the wear loss increase with the increase of particles kinetic energy which is proportional to the velocity power of two. Weight loss $=$ constant $x v^{n}$,

where $\mathrm{v}$ is the impact velocity of particles, and usually the constant $n, 2^{\leq} \mathrm{n} \geq 2.5$. and $\mathrm{n}$ depends on material and erosion conditions.

However, control maximum impact velocity of particles can reduce the slurry erosive wear rate with a resizable value.

\subsection{Effect of time duration}

The mud slurry erosive wear rates of stainless steel 316 with different time duration at a different specimens impact velocities $2.3,5.75 \mathrm{~m} / \mathrm{s}$ are shown in Figures (9). It can be generally observed that the wear rate (weight loss) can be divided into four stages, the first stage which has no weight loss but it has plastic deformation due to particles impact on material surface. In the second stage it is observed that an increase in time duration results in an increase the slurry erosion wear rate ( weight loss ). Third stage has a slightly weight loss, which is due to the effect of particles kinetic energy on increasing the material surface hardening which resists the wear at this stage. Steady-state conditions with low wear rates for most of the lifetime of the equipment. The fourth stage it can be observed that an increase in time duration results in an increase in the wear rate (weight loss) which is due to the effect of particles kinetic energy on the surface for a long time which causes weight loss due to separation from surface.

The sand slurry erosive wear rates of stainless steel 316 with different time duration ( each 2 hours up to 32 ) at a different specimens rotation 200, 500 r.p.m ( impact velocities $2.3,5.75 \mathrm{~m} / \mathrm{s}$ ) as shown in Figures (10). It can be generally observed that the wear rate (weight loss) can be divided into three stages. The first stage it can be observed that increasing time duration results in an increase in the slurry erosion wear rate (weight loss). The second stage has a slightly weight loss, that is due to the effect of particles kinetic energy on increasing material surface hardening which resist the wear at this stage. A steady-state conditions with low wear rates is observed for most of the lifetime of the equipment. In the third stage it is observed that an increase in time duration results in an increase in the wear rate (weight loss ) that is due to the effect of particles kinetic energy on surface for long time which cause weight loss due to separating from surface. Also Figure (11) shows in general that an increase in duration time results in an increase in weight loss.

The effect of duration time is mean lifetime of actual parts, which sever from erosion.

\subsection{The effect of impact angle}

The impact angle is the angle between the eroded material surface and the direction of the particle immediately before impact. The effect of impact angle on erosion rate of stainless steel 304 is studied, and results are shown in Figures (11), and (12). It is evident from the figures that impact angle has a significant influence on erosion. The effect divided into three 
different regions. The first region from $20^{\circ}$ up to $44^{\circ}$, it shows that increasing the impact angle results in increasing the weight loss. The second region shows that the maximum erosion is occurring at an impact angle between $45^{\circ}$ and $49^{\circ}$, in the third region, it is clear that the weight is less with increasing the impact angle from $50^{\circ}$ up to $90^{\circ}$. So it is concluded that this is "ductile mode of erosion wear".

Also it is clear from SEM photograph that the effect of different impact angles on the surface of specimens. Figures (13), (14) are SEM photographs for plates specimens were tested up to 9 hours, the relative velocity was $2.3 \mathrm{~m} / \mathrm{s}$, using sand particles maximum size $550 \mu \mathrm{m}$ with water $40 \mathrm{wt} . \%$. and the impact angles were $33^{\circ}$, and $90^{\circ}$ respectively. The Figures show that wear for impact angle $33^{\circ}$ is higher slurry erosive wear rate than impact angle $90^{\circ}$. That is due to impact angle $33^{\circ}$ gets good angle for cutting and separate small parts from surface, But for impact angle $90^{\circ}$ the photographs show much more plastic deformation on material surface due to particles impact perpendicular to surface without weight loss. Figures (15), (16) are SEM photographs for plates specimens were tested up to 18 hours, the impact angles were $49^{\circ}$, and $90^{\circ}$ respectively. The Figures shows that wear for impact angle $49^{\circ}$ is higher slurry erosive wear rate than impact angle $90^{\circ}$. That is due to impact angle $49^{\circ}$ is a very good angle for cutting and separate small parts from this material surface than angle $33^{\circ}$, But for impact angle $90^{\circ}$, the photographs show much more plastic deformation on material surface and small wear in the surface for more than 9 hours test.

However, control impact angle can reduce the slurry erosive wear rate when understanding the material behavior with the slurry properties.

\section{CONCLUSION}

The previous experimental results investigate the effect of the test duration time, the slurry type, the relative velocity, and the impact angle on erosion.

For the particle type results show that increasing particles hardness results in an increase in the specimen's weight loss for different velocities and time. Also the wear rate is not the same for different particles. For the same testing conditions it is concluded that :-

1) Experimental work results using the present test rig are valid to investigate the different parameters on erosion, such as; test duration time, particles specifications (sizes, type, and concentration), different specimen materials and geometry, different impact angles and different particles velocities.

2) Increasing the particles hardness increases the weight loss rate.

3) Reducing the particles velocity results in a reasonable effect on weight loss.

4) Impact angle has a great effect on erosion. For slurry pipe elbow it is prefered to design the elbow angle to avoid maximum wear rate according to the ductile or brittle elbow materials and flow conditions.

5) The test time affects the erosion rate. It can be part for erosion resistance design according to the required lifetime with easy and fast replace.

\section{REFERENCES}

1- Hari Prasad Neopane "Sediment Erosion in Hydro Turbines" PhD thesis, Faculty of Engineering Science and Technology, Norwegian University of Science and Technology (NTNU), Trondheim, Norway March 2010

2- Lalit Upadhayay, Satish Kumar "Numerical Investigation of Silicon Carbide Particle Suspension Behavior for Enhancing Uniform Suspension in Erosion Wear Test Rig" International Journal of Advanced Research in Engineering and Applied Sciences Vol. 4 | No. 6 | June 2015.

3- A.P. Harsha, U.S. Tewari, B. Venkatraman "Solid particle erosion behaviour of various polyaryletherketone composites" a Industrial Tribology Machine Dynamics and Maintenance Engineering Centre, Indian Institute of Technology, HauzKhas, New Delhi 110016, India Defense Metallurgical Research Laboratory, Kanchanbagh, Hyderabad 500058, India Received 30 July 2002; accepted 5 February 2003.

4- Heinz W. Bargmann "The mechanics of erosion by liquid and solid impact" International Journal of Solids and Structures, El-Sevier, Vol. 29, Issue 14-15, 1992, pp. 1685-1698 
5-G.F. Truscott "A literature survey on abrasive wear in hydraulic machinery" Wear, Vol.20. Issue 1, May 1972, pp 29-50

6- Sunil Kumar and . Jasbir Singh Ratol "Effects of Tribological Parameters on Slurry ErosionBehaviour of Uncoated and Coated Materials: A Review ", Materials Engineering Materiálové inžinierstvo 20 (2013) 119-131

7- Mousab Hadad, Reinhard Hitzek, Johann. Michler, Jacky Lesage3 "Tribological Behavior of Sandwich Structured WC-CO-CR Thermally Sprayed Coatings" EMPA20090392 ECOTRIB 2009- 2end European Conference on Tribology, June 7-10, Pisa, Ialy

8- H. Imrek, M. Bagci, O.M. Khalfan "Experimental investigation of effects of external loads on erosive wear" JAMME Journal of Achievements in Materials and Manufacturing Engineering Volume 32 Issue 1 January 2009.

9- M.C.Lin, ,L.S.Chang ,H.C.Lin ,C.H.Yang ,K.M.Lin "Astudyofhigh- speed slurry erosion of NiCrBS ithermal-sprayed coating" Surface \& Coatings Technology 201 (2006) 3193 - 3198 , Received 21 April 2006; accepted in revised form 27 June 2006 Available online 2 August 2006.

10-Pramod A. Thakur, Hitesh S. Khairnar, Dr. E.R. Deore, S.R. More "Development of Slurry Jet Erosion Tester to Simulate the Erosion Wear due to Solid-Liquid Mixture" International Journal of Novel Research in Engineering and Science Vol. 2, Issue 1, pp: (1420), Month: March 2015 - August 2015.

11- Gulovleen Singh, Roshan Lal Virdi, Khushdeep Goyal "Experimental Investigation of Slurry Erosion Behaviour of Hard Faced AISI 316L Stainless Steel" Universal Journal of Mechanical Engineering 3(2): 52-56, 2015 DOI: 10.13189/ujme.2015.030204

12- Randall S. Lynn, Kien K. Wong and Hector MCI. Clark "On the particle size effect in slurry erosion" Wear, I49 (1991) 55-71 55, Received February 23, 1991

13- C.S. Ramesh*, R. Keshavamurthy "Sand Slurry Erosive Wear Behavior of Hot Extruded Al6061-SiC Composites" Journal of Minerals \& Mateials Characterization \& Engineering, Vol. 10, No.6, pp.493-505, 2011

14- Bhupendra K. Gandhi "An Accelerated Erosion Wear Test Rig For High Impact Velocities" ICHPSD-2015 528 Indian Institute of Technology, Roorkee - 247667 INDIA International Conference on Hydropower for Sustainable Development Feb 05-07, 2015, Dehradun 529

15-Y. M. Abd-Elrhman, A. Abouel-Kasem, K. M. Emara and S. M. Ahmed, "Effect of Impact Angle on Slurry Erosion Behavior and Mechanisms of Carburized AISI 5117 Steel", Journal of Tribology, Vol.136, Part 1, 2013

16- H.J. Amarendra, G.P. Chaudhari, S.K. Nath, "Synergy of cavitation and slurry erosion in the slurry pot tester" Wear290-291(2012)25-31Accepted 30May2012

17- J.F. Santa, J.C. Baena, A. Toro "Slurry erosion of thermal spray coatings and stainless steels for hydraulic machinery" Wear 263 (2007) 258-264

18- Mehdi Azimian and Hans-Jörg Barta "CFD simulation and experimental analysis of erosion in a slurry tank test rig" EPJ Web of Conferences 45, 01009 (2013) DOI: 10.1051/ epjconf/ 20134501009 published by EDP Sciences, 2013

19- Yoshiro Iwai, Tohru Matsubara, Yuichi Hirai, Sture Hogmark, "Development of a new type micro slurry-jet erosion (MSE) tester for evaluation of wear properties of hard thin coatings" Japan Society for the Promotion of Science (JSPS) (No. 18360076).

20- Murugan K, Ragupathy A , Balasubramanian V and Sridhar K "Evaluating Effects of Water Jet Erosion Parameters on Erosion Behaviour of Naval Brass Alloy" Journal of Manufacturing Engineering, March 201 5, Vol. 10, Issue. 1, pp 43-48.

21- Kendrick H. Light B.S. "Development of A Cavitation Erosion Resistant Advanced Material System" M.S . thesis The University of Maine August, 2005

22- S.S. R ajahram, T.J. Harvey, R.J.K. Wood Erosion-corrosion resistance of engineering materials in various test conditions" Wea $\mathrm{r} 267 \quad\left(\begin{array}{lllllll}2009 & 24 & 4 & - & 2 & 54\end{array}\right.$ 23- A. Toro a, A. Sinatora, D.K. Tanaka, A.P. Tschiptschin "Corrosion-Erosion of Nitrogen Bearing Martensitic Stainless Steels in Seawater-Quartz Slurry" Wear 251 (2001) 1257-1264 24- Maksim Antonov, Margaret Stack and Irina Hussainova "Erosion-corrosion of Cr3C2-Ni cermets in salt water" Proc. Estonian Acad. Sci. Eng., 2006, 12, 3-1, 176-187 Received 24 October 2005, in revised form 6 March 2006 